Ambiente \& Água - An Interdisciplinary Journal of Applied Science
ISSN 1980-993X - doi:10.4136/1980-993X
www.ambi-agua.net
E-mail: ambi.agua@gmail.com

\title{
Sistemas Alagados Construídos em Batelada: remoção de Demanda Bioquímica de Oxigênio e regulação de pH no tratamento de efluentes de laticínios
}

\author{
doi: 10.4136/ambi-agua.1511
}

Received: 22 Sep. 2014; Accepted: 29 Jan. 2015

\author{
Henrique Vieira de Mendonça ${ }^{1 *}$; Celso Bandeira de Melo Ribeiro ${ }^{1}$; \\ Alisson Carraro Borges ${ }^{2}$; Ronaldo Rocha Bastos ${ }^{1}$ \\ ${ }^{\mathbf{1}}$ Universidade Federal de Juiz de Fora (UFJF), Juiz de Fora, MG, Brasil \\ ${ }^{2}$ Universidade Federal de Viçosa (UFV), Viçosa, MG, Brasil \\ *Autor correspondente: e-mail: henriqueufv@gmail.com, \\ celso.bandeira@ufjf.edu.br, borges@ufv.br, ronaldo.bastos@ufjf.edu.br
}

\section{RESUMO}

Este trabalho foi desenvolvido, com sistemas alagados construídos (SACs), para avaliar a eficiência no tratamento de efluentes de laticínios. Procurou-se avaliar a influência de substratos e espécies vegetais, sobre a eficiência na remoção de DBO e regulação de $\mathrm{pH}$, em seis unidades experimentais operadas, em batelada, em escala piloto. Os seis SACs foram montados em tanques de polietileno etileno de alta densidade (PEAD) com volume total de 100 litros, para tratamento de águas residuárias de laticínios (ARC). Os substratos utilizados foram a brita $\mathrm{n}^{\circ} 0$ em três dos SACs e brita $\mathrm{n}^{\circ} 0$ e areia em outros três, na proporção de $80 \%$ brita e $20 \%$ areia. Quatro unidades experimentais foram cultivadas e duas mantidas como testemunhas. As espécies selecionadas foram as macrófitas Typha dominguensis (taboa) e o Hedychium coronarium (lírio do brejo). A eficiência média mínima encontrada no tratamento foi de $77,8 \%$ e máxima de $95,2 \%$, em termos de remoção de DBO, e foi mantida a faixa de pH entre 5 e 9, conforme estabelecido pela Resolução CONAMA 430/2011, para lançamento e curso de água. Os seis tratamentos apresentaram remoção de compostos carbonáceos biodegradáveis semelhantes não havendo diferenças significativas entre tratamentos com nível de confiança de 95\%. O estudo mostrou que os SACs operando em batelada podem ser utilizados no tratamento de águas residuárias de laticínios para a remoção de DBO e regulação do $\mathrm{pH}$.

Palavras-chave: eficiência, macrófitas, tamponamento.

\section{Constructed Wetlands Systems Batch: removal of Biochemical Oxygen Demand and pH regulation for treatment dairy effluent}

\section{ABSTRACT}

This work assessed the effectiveness of using constructed wetlands (CW's) to treat dairy effluent. The purpose of the research was to evaluate the influence of substrates and cultivated plants on the efficiency of Biochemical Oxygen Demand (BOD) removal and $\mathrm{pH}$ regulation in six experimental units operating at pilot scale. Six CW's for dairy sewage treatment were constructed in 100-liter High-Density Polyethylene Ethylene (HDPE) tanks. Three 
constructed wetlands containing fine gravel $(0 \mathrm{~mm})$ and another three with a mix of $20 \%$ sand and $80 \%$ fine gravel $(0 \mathrm{~mm})$ were used in the filtering stage. Four experimental units were planted with the macrophytes Typha dominguensis (cattail) and Hedychium coronarium (pond lily), the selected plants for this study, and two others were maintained as control units. A minimum average of $77.8 \%$ and a maximum of $95.2 \%$ BOD efficiency removal were achieved and a $\mathrm{pH}$ range of 5 to 9 was maintained as required by the Brazilian Resolution CONAMA N. $430 / 2011$ in order to release the effluent into a waterway. The six treatments showed similar removal of biodegradable carbonaceous compounds with no significant differences between the treatments at a 95\% confidence level. This work showed that CW's operating in batch can be used to treat dairy raw water for BOD removal and $\mathrm{pH}$ regulation.

Keywords: buffering, efficiency, macrophytes.

\section{INTRODUÇÃO}

Considerando o potencial poluidor de uma indústria de laticínios, os efluentes líquidos gerados nos mais diversos setores de produção são considerados os principais responsáveis pela poluição deste tipo de agroindústria.

Segundo Mendonça (2011), uma unidade de beneficiamento de leite de pequeno porte que processa aproximadamente $10.000 \mathrm{~L}$ de leite por dia, sendo a DBO do efluente da ordem de $2.000 \mathrm{mg} \mathrm{L}^{-1}$ gera uma quantidade de efluentes 3 vezes maior $(30.000 \mathrm{~L})$ que o volume de matéria prima processada por dia e possui poder poluente semelhante ao de um núcleo populacional de aproximadamente 1.111 pessoas, considerando que em média cada habitante produza $54 \mathrm{~g}$ de DBO dia ${ }^{-1}$, ficando evidente a necessidade do tratamento dos efluentes antes de seu lançamento em curos de água.

Uma biotecnologia prática e de baixo custo para remoção de $\mathrm{DBO}$ da água residuária de laticínios (ARL) são os sistemas alagados construídos (SACs). Este sistema ainda tem como vantagem a remoção de nutrientes como nitrogênio e fósforo da ARL (Mendonça et al., 2012) e também capacidade de manutenção do $\mathrm{pH}$ dentro de limites aceitávies e preconizados pela legislação federal CONAMA 430/2011 (Brasil, 2011), para lançamento de efluentes em cursos de água.

Os mecanismos envolvidos no tratamento de águas residuárias em sistemas alagados construídos são: filtração, degradação microbiana da matéria orgânica por biofilmes aderidos ao substrato, absorção de nutrientes pelos rizomas das vegetações e microrganismos, adsorção e dessorção, entre outros.

Nos últimos anos, o uso de sistemas lagados construídos (SACs) para o tratamento da ARL tem ganhado popularidade, devido a seu baixo custo de implantação e monitoramento em comparação aos demais sistemas convencionais. Nos Estados Unidos e Europa, o uso de SACs vem sendo registrado em um grande número de indústrias de laticínios, apresentando resultados promissores (Healy e Cawley, 2002).

$\mathrm{Na}$ Irlanda, o método mais comum de tratamento da ARL era a disposição no solo. Atualmente este método vem sendo substituído pelos SACs, por estes fornecerem desempenho de tratamento eficaz, proporcionando também redução de espaço físico para implantação e aumento substancial das taxas de carga orgânica em termos de DBO a serem aplicadas (Healy et al., 2007).

Na província de Reggio Emilia, Itália, Mantovi et al. (2003), relataram o uso de um sistema alagado construído para tratar a ARL de uma queijaria. O sistema possuía um pré-tratamento composto por um decantador tipo Imhoff e dois SACs, cada um com $72 \mathrm{~m}^{2}$, preenchidos com cascalho lavado e brita $\mathrm{n}^{\circ} 3$. Ambos os sistemas alagados foram cultivado com caniço d'água (Phragmites australis). Os resultados encontrados foram considerados promissores e os autores apontaram esta biotecnologia como apropriada para reduzir material 
orgânico biodegradável contido na ARL, atingindo remoções de 93,7\% de DBO da água residuária. Neste estudo o autor aplicou uma taxa de carga orgânica (TCO) de $19 \mathrm{Kg} \mathrm{DBO} \mathrm{ha}{ }^{1} \mathrm{~d}^{-1}$, adotando um tempo de detenção hidráulica (TDH) de 10 dias.

Na Lituânia, Gasiunas et al. (2005), relataram o uso de um sistema de $100 \mathrm{~m}^{2}$ com substrato composto por areia e também cultivados com Phragmites australis, no tratamento da ARL. Os autores obtiveram na pesquisa uma remoção de 96,8\% de DBO, do efluente bruto. Foi adotada uma TCO de $221 \mathrm{Kg}$ DBO ha $^{-1} \mathrm{~d}^{-1}$, e um TDH de 10 dias.

Drizo et al. (2006) ao estudarem sistemas cultivados com Schoenoplectus fluviatilis para tratar efluentes de leite em Vermont, Estados Unidos, encontraram resultados indicativos de que os sistemas possuem relevante potencial para utilização mesmo em temperaturas extremamente reduzidas da região do estudo.

Reaves (1995), monitorando SACs de escoamento subsuperfical em LaGrange County, no estado de Indiana, nos Estados Unidos, observou uma redução de 62 a $81 \%$ na DBO, fazendo uso de um TDH de 100 dias com uma TCO de 6,2 $\mathrm{Kg} \mathrm{DBO}_{\text {ha }}{ }^{-1} \mathrm{~d}^{-1}$. Foram utilizadas três parcelas, ocupando uma área total de 0,11 ha, onde os leitos foram cultivados com Phalaris arundinacae (capim amarelo).

Em uma pesquisa realizada na Universidade de Connecticut (EUA), Neafsey e Clausen (1994), utilizando três células em paralelo, ocupando uma área total de 0,037 ha, adotando um TDH de 27 dias, cultivando em consórcio as macrófitas Typha spp., Phragmites spp. e Scirpus americanus, conseguiram uma remoção de 56,6 a 99,1\% na DBO.

Matos et al. (2010a) realizaram um estudo com SACs, na Universidade Federal de Viçosa, variando a TCO entre 66 e $570 \mathrm{Kg} \mathrm{DBO} \mathrm{ha}{ }^{-1} \mathrm{~d}^{-1}$ atingindo uma remoção superior a $85 \%$ de DBO, utilizando um sistema com escoamento sub superficial cultivado com as forrageiras Cynodon dactylon Pers (tifton-85) e Pennisetum purpureum Schum (Napier), com um TDH de 4,8 dias.

Devido a carência de pesquisas sobre o tratamento da ARL por SACs em condições de clima tropical, com ênfase na remoção de DBO e regulação de $\mathrm{pH}$, objetivou-se com esta pesquisa, avaliar o potencial destes sistemas para remover e regularizar, estes parâmetros, em condições de clima tropical, no município de Juiz de Fora - MG.

\section{MATERIAL E MÉTODOS}

O experimento foi conduzido nas instalações do Laticínio Flórida no município de Juiz de Fora - MG, com coordenadas geográficas $21^{\circ} 40^{\prime} 45^{\prime \prime}$ de latitude sul e $43^{\circ} 26^{\prime} 31^{\prime \prime}$ de longitude oeste. No laticínio são fabricados os seguintes produtos: doce de leite em pasta e barra, leite condensado e leite pasteurizado tipo C.

Nesta pesquisa, a água residuária de laticínios (ARL) aplicada aos SACs foi submetida apenas ao tratamento preliminar, composto por grades finas em alumínio de 9,52 x 25,4 mm, com espaçamento de $25 \mathrm{~mm}$, largura de $0,30 \mathrm{~m}$, altura de $0,60 \mathrm{~m}$ e ângulo de inclinação de $60^{\circ}$, desarenador com $0,30 \mathrm{~m}$ de comprimento e 1,55 $\mathrm{m}$ de largura e uma caixa de gordura de alvenaria, com 1,37 m de comprimento e $0,84 \mathrm{~m}$ de largura, com TDH médio de 30 minutos.

As unidades experimentais foram constituídas por seis leitos horizontais, instalados em paralelo. Os SACs foram construídos por meio de recipientes de polietileno etileno de alta densidade (PEAD) de $200 \mathrm{~L}$ de capacidade, cortados transversalmente, formando duas calhas, cada uma com o volume total de $100 \mathrm{~L}$ e volume útil de aproximadamente $47 \mathrm{~L}$, descontando as bordas livres e a camada de brita superficial que não entrou em contato com o efluente $(10 \mathrm{~cm})$.

Após a inserção do meio suporte nos reservatórios, estes passaram a apresentar o volume de $16 \mathrm{~L}$, considerando a porosidade média do material. 
A brita utilizada nesta pesquisa foi retirada de jazidas de granito, rochas ígneas compostas basicamente por biotita e feldspato, minerais que possuem ferro e alumínio em sua estrutura molecular. A porosidade para brita $\mathrm{n}^{\circ} 0$ (Pedrisco), com granulometria $4,8 \mathrm{~mm}$ e areia média lavada, com granulometria $2,4 \mathrm{~mm}$, foram de $0,35 \mathrm{~m}^{3} \mathrm{~m}^{-3}$ e $0,20 \mathrm{~m}^{3} \mathrm{~m}^{-3}$ respectivamente.

Cada unidade apresentava seção transversal semicircular com raio interno aproximado de 0,24 m e comprimento de 1,10 metros, com uma declividade média de $0,05 \%$ sobre o solo.

Foram utilizados como substrato: brita $\mathrm{n}^{\circ} 0$ em três dos SACs e brita e areia média

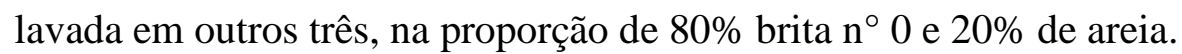

As espécies vegetais selecionadas para o cultivo foram a Typha dominguensis (taboa) e a Hedychium coronarium (lírio do brejo).

Quatro leitos foram plantados, sendo dois com cada espécie selecionada e dois sistemas foram mantidos sem vegetação, servindo como testemunhas.

Na Tabela 1 sumariza-se a concepção das unidades experimentais de tratamento.

Tabela 1. Concepções de tratamento adotadas no experimento (Mendonça, 2012).

\begin{tabular}{|c|c|c|c|c|}
\hline Sistema & Substrato* & Vegetação & Volume & TC \\
\hline SAC1 & $\mathrm{B}$ e $\mathrm{A}$ & Taboa & $7,5 \mathrm{~L}$ & 2 dias \\
\hline $\mathrm{SAC} 2$ & $\mathrm{~B}$ e $\mathrm{A}$ & Lírio & $7,5 \mathrm{~L}$ & 2 dias \\
\hline SAC3 & B & Taboa & 7,5 L & 2 dias \\
\hline SAC4 & B & Lírio & 7,5 L & 2 dias \\
\hline SAC5 & B & Testemunha & $7,5 \mathrm{~L}$ & 2 dias \\
\hline SAC6 & $\mathrm{B}$ e $\mathrm{A}$ & Testemunha & 7,5 L & 2 dias \\
\hline
\end{tabular}

Na Figura 1 é mostrada a disposição dos SACs na área experimental conforme a descrição da Tabela 1 .

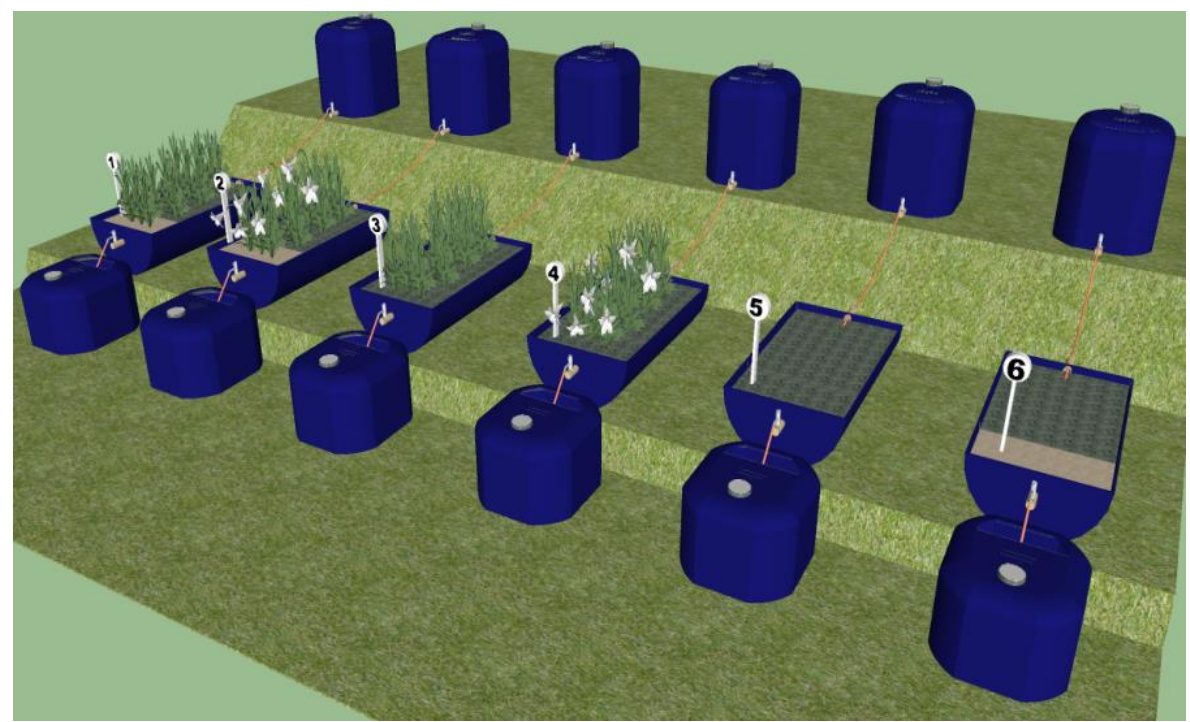

Figura 1. Arranjo e disposição dos SACs na área experimental para tratamento da ARL e demonstrativo do uso de somente brita, ou brita e areia e das espécies cultivadas. 
A média da água residuária após passagem pela caixa de gordura foi de $1.701 \mathrm{mg} \mathrm{L}^{-1}$ (considerando 10 amostras), apresentando um desvio padrão de $\pm 1.056,0$. Já a faixa de $\mathrm{pH}$ afluente aos sistemas obteve uma média de 5,2 (considerando 25 amostras) e desvio padrão de $\pm 1,9$.

O volume aplicado aos sistemas 7,5 L, foi empregado para manter a taxa de aplicação de carga orgânica em torno de $232 \mathrm{~kg} \mathrm{ha}^{-1} \mathrm{~d}^{-1}$, levando em consideração uma DBO de $1.701 \mathrm{mg} . \mathrm{L}^{-1}$, valor médio da água residuária gerada pelo empreendimento.

O método empregado na operação dos SACs, descontínuo, foi realizado por meio de uma adaptação do método em batelada, onde a ARL ao ser aplicada na zona de entrada dos leitos, expulsava o efluente tratado para os reservatórios a jusante dos sistemas, sem haver esvaziamento das unidades experimentais. O tempo de ciclo (TC) adotado foi de 2,0 dias, aplicando a ARL por meio de registros conectados a mangueira.

Anteriormente à aplicação da ARL nos sistemas, durante quinze dias consecutivos foi realizada a lavagem com água limpa do substrato, visando desobstrução do meio filtrante.

Posteriormente, por 30 dias fez-se saturação dos tanques diariamente, com o efluente a jusante do sistema preliminar, objetivando-se o desenvolvimento de um biofilme adaptado às condições do biossistema construído, antes de sua efetiva operação.

Em seguida, foram plantadas as espécies vegetais por meio de propágulos vegetativos (rizoma + caule) com aproximadamente, $25 \mathrm{~cm}$ de comprimento, no caso da taboa. O lírio do brejo foi inserido ao substrato, plantando-se mudas jovens entre 30 e $40 \mathrm{~cm}$, ambas as espécies foram cultivadas com um adensamento de plantio de 12 propágulos por metro quadrado $\left(\mathrm{m}^{2}\right)$.

Após o plantio das vegetações, foi iniciada a operação dos sistemas, com ciclos de 48 horas em regime de bateladas, monitorando por durante 260 dias valores $\mathrm{pH}$ e 140 dias valores de DBO.

A regra operacional foi realizada da seguinte forma: a ARL foi coletada no tanque de equalização a uma profundidade de 0,5 metros, para posterior armazenamento nos reservatórios de $60 \mathrm{~L}$ em PEAD indicados por (1) na Figura 2A. Logo após, abria-se lentamente os registros dos reservatórios, permitindo o escoamento do efluente pelas mangueiras (2) por gravidade até os SACs indicados por (3). A ARL depois de ocupar o volume de vazios dos leitos, permanecia estática por dois dias em seu interior. Ao completar 48 horas iniciava-se um novo ciclo. Na medida em que a ARL ia ocupando o interior dos leitos, gradativamente o efluente tratado deslocava-se para os reservatórios de coleta (4), onde se realizava as inspeções de qualidade da água residuária tratada. Um detalhe do escoamento temporário no meio poroso é apresentado na Figura 2B.

Para avaliar se houveram diferenças significativas entre as médias das eficiências dos tratamentos dos SACs vegetados e não vegetados, fez-se uso de análise de variância ANOVA para medidas repetidas no tempo e os testes de Dunnett e Student-Newman-Keuls.

Neste estudo foram analisados 2 parâmetros, sendo eles, DBO e potencial hidrogeniônico $(\mathrm{pH})$.

Para DBO foram realizadas 10 amostragens espaçadas aproximadamente de $15 \mathrm{em}$ 15 dias, e os resultados obtidos pelo método iodométrico, sendo quantificado a concentração de oxigênio dissolvido antes e após a incubação, sob temperatura de $20^{\circ} \mathrm{C}$ durante cinco dias.

Para $\mathrm{pH}$ foram realizadas 25 amostragens para cada sistema avaliado, sendo sua determinação executada em campo utilizando-se um medidor de $\mathrm{pH}$ digital da marca CapLab modelo PG 1.400 . 

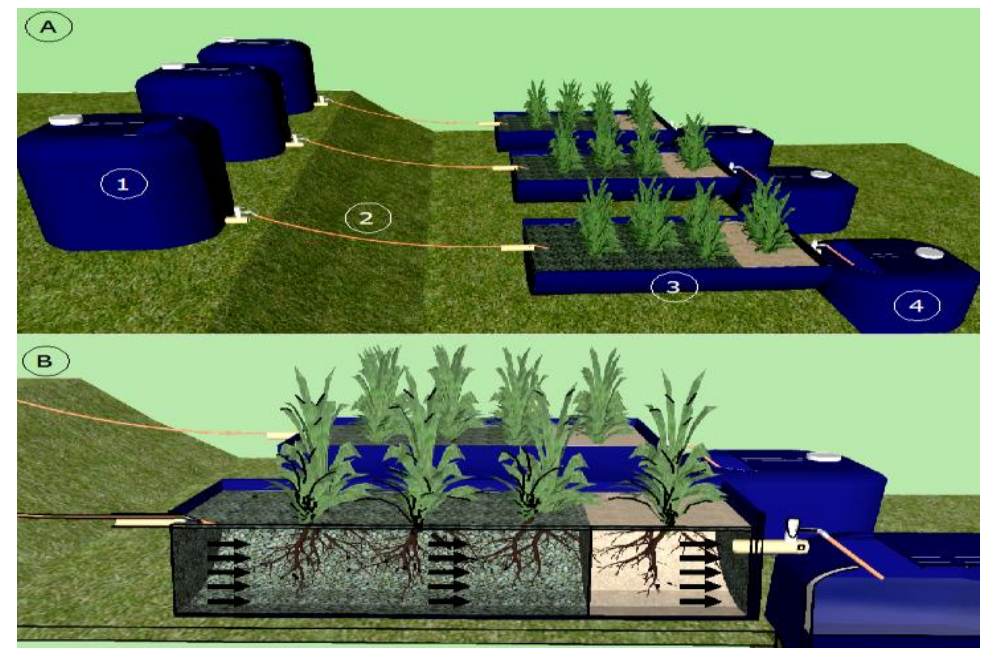

Figura 2. (A) Diagrama esquemático do sistema operacional: (1) reservatório da ARL pré-tratada preliminarmente, (2) registros e mangueira de condução da água residuária para os sistemas alagados construídos (SACs), (3) SACs, (4) reservatório de coleta da ARL tratada nos SACs. (B) Detalhe do escoamento subsuperficial temporário no leito poroso dos SACs.

As análises laboratoriais foram realizadas em conformidade com as recomendações de APHA et al. (1998).

\section{RESULTADOS E DISCUSSÃO}

Os resultados das eficiências de tratamento de cada parâmetro analisado são apresentados a seguir.

\subsection{Variação do Potencial Hidrogeniônico (pH)}

Houve ampla variação das faixas de $\mathrm{pH}$ do efluente bruto (afluente aos SACs), apresentando valores de 3,0 a 11,0. Entretanto, independente da variação do $\mathrm{pH}$ afluente, foi verificado que a ARL aplicada apresentou condição predominantemente ácida durante o período experimental com média 5,2 (Tabela 2).

Tabela 2. Valores médios, mínimos e máximos e desvio padrão (DP) no afluente e efluente dos sistemas alagados construídos (SACs) utilizados no tratamento das águas residuárias de laticínios.

\begin{tabular}{lcccc}
\hline Sistema & Média & Máximo & Mínimo & DP \\
\hline Afluente & 5,0 & 11,0 & 3,0 & $\pm 1,90$ \\
SAC1 & 6,0 & 5,5 & 5,2 & $\pm 0,81$ \\
SAC2 & 6,0 & 8,0 & 5,0 & $\pm 0,92$ \\
SAC3 & 6,0 & 7,2 & 5,2 & $\pm 0,67$ \\
SAC4 & 6,0 & 8,2 & 5,1 & $\pm 0,93$ \\
SAC5 & 6,0 & 8,5 & 5,0 & $\pm 0,94$ \\
SAC6 & 6,0 & 8,7 & 5,1 & $\pm 1,00$ \\
\hline
\end{tabular}


O aspecto ácido do afluente foi atribuído ao lançamento de soro de leite ácido, junto à água residuária. As faixas de $\mathrm{pH}$ com características básicas são atribuídos a descargas de soda cáustica, produto comumente usado em limpeza de tubulações neste tipo de indústria.

Os efluentes do sistema piloto apresentaram valor médio de $\mathrm{pH}$ 6,0, dentro da faixa de sobrevivência de muitas das bactérias responsáveis pelo tratamento do resíduo líquido de 4,0 a 9,5 (Mansor, 1998), e também dentro da faixa ótima para crescimento bacteriano em torno da neutralidade $(6,5$ e 7,5) (Metcalf \& Eddy, 1991). Estes autores destacam que a maioria das bactérias não suporta valores de $\mathrm{pH}$ acima de 9,5 e abaixo de 4,0. Mesmo quando se aplicou a ARL com pH 3,0 e 11,0, os sistemas foram capazes de tamponar a solução nos SACs, mantendo o meio propício ao desenvolvimento microbiológico, produzindo um efluente com pH apto ao lançamento em curso de água em conformidade com a resolução CONAMA 430/2011, entre 5 e 9.

Matos et al. (2010a; 2008) encontraram valores médios de $\mathrm{pH}$ entre 6,55 a 6,85 estudando SACs de escoamento sub superficial cultivados com forrageiras. As faixas encontradas pelos autores encontram-se próximas às do presente estudo, indicando boa capacidade de tamponamento dos leitos no tratamento da ARL.

De acordo com a análise de variância não houve diferença significativa $(\mathrm{p}>0,05)$ entre os valores de $\mathrm{pH}$ do efluente tratado pelas seis unidades experimentais. Sendo assim, não houve influência das vegetações ou dos substratos utilizados na variação dos valores de $\mathrm{pH}$.

Matos et al. (2010b) encontraram faixas de $\mathrm{pH}$ no efluente da suinocultura tratado por SACs variando entre 6,5 e 6,7, sendo os valores afluentes da ordem de 3,7 a 4,8, indicando que a presença de matéria orgânica proporcionou tamponamento dos leitos. Nesta pesquisa a capacidade de tamponamento dos sistemas também foi atribuída à presença do material orgânico proveniente da ARL, associado a seu $\mathrm{pH}$ predominantemente ácido $(5,2)$ junto aos leitos.

Por meio da análise da Figura 3, pode ser observado a amplitude da variação do $\mathrm{pH}$ do afluente ao longo do tempo, assim como a capacidade dos leitos de manter a faixa de $\mathrm{pH}$ do efluente tratado entre da faixa de 5 a 9 preconizado pela Legislação Federal CONAMA 430/2011, para lançamento de efluentes em curso de água.

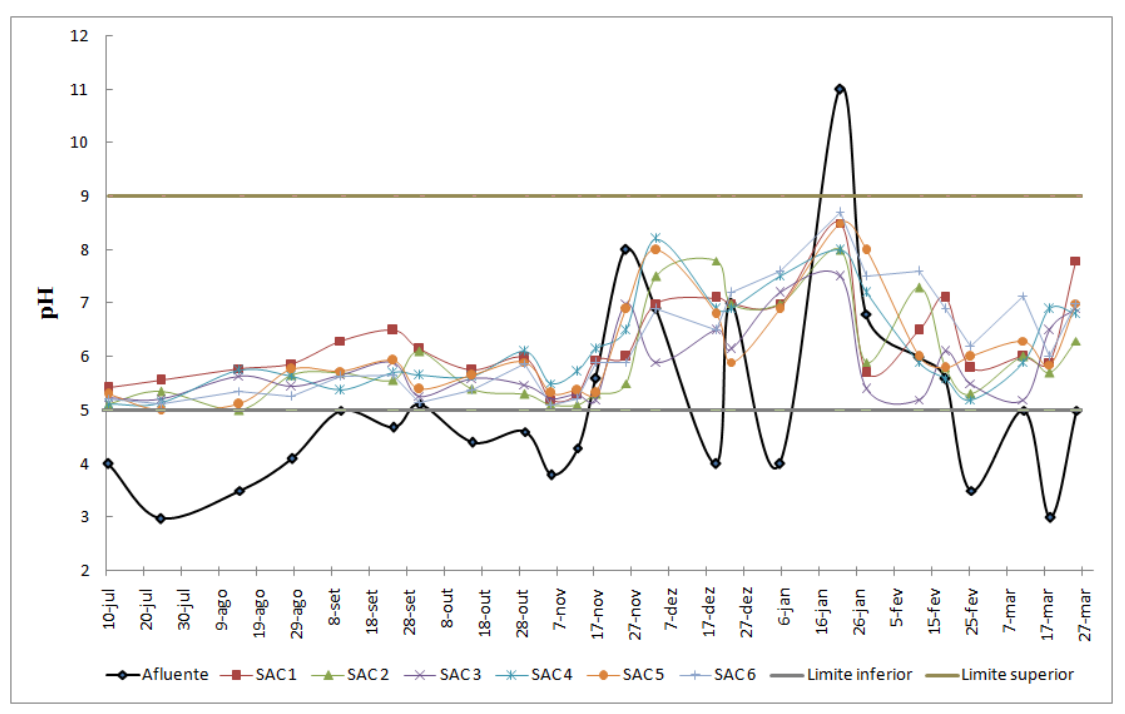

Figura 3. Série temporal da variação do $\mathrm{pH}$ durante 260 dias de operação dos SACs (julho de 2009 a março de 2010), evidenciando os limites superior e inferior para lançamento de efluentes em curso de água entre 5 e 9 preconizado pela resolução CONAMA 430/2011. 
Os estudos em SACs realizados por Matos et al. (2010b) com água residuária da suinocultura (ARS) e Matos et al. (2010a) com ARL em escoamento contínuo, também não apresentaram diferença significativa das faixas de $\mathrm{pH}$ entre as parcelas estudadas para o $\mathrm{pH}$ do efluente. Nos estudos acima citados e também nesta pesquisa em regime intermitente, as faixas de $\mathrm{pH}$ mantiveram-se próximas da neutralidade na saída dos sistemas. Tal fato é também reportado a degradação predominantemente anaeróbia no meio, favorecendo a produção de ácidos orgânicos voláteis no processo. Tais ácido não foram acumulados no meio causando declínio do $\mathrm{pH}$, permanecendo este numa faixa favorável à decomposição do material orgânico biodegradável, ao longo da operação dos SACs.

\subsection{Remoção da Demanda Bioquímica de Oxigênio (DBO)}

De forma geral os seis SACs avaliados apresentaram relevante remoção de material carbonáceo biodegradável. A eficiência máxima encontrada foi de 95,2\% atribuído ao SAC 3 cultivado com taboa com substrato constituído por brita $n^{\circ} 0$, a menor de $77,8 \%$ para os $\mathrm{SAC}$ 6 (testemunha) tendo como substrato brita $\mathrm{n}^{\circ} 0$ e areia média lavada. Em média, ao longo de todo o experimento o SAC 1 cultivado com taboa tendo como substrato brita $\mathrm{n}^{\circ} 0$ e areia média lavada, apresentou melhor regularidade no tratamento, com os melhores resultados, alcançando eficiência média de $91,5 \%$ na remoção de DBO. Este sistema apresentou maior estabilidade com menores variações na amplitude da eficiência.

A maior estabilidade do SAC 1 pode ser verificada também pelo seu menor valor do desvio padrão $( \pm 2,6)$ em comparação com os demais sistemas, como evidenciado na Tabela 3. Os SACs 3 e 5 apresentaram a segunda melhor eficiência média com 90,4\%, o SAC 3 possuía como substrato brita $\mathrm{n}^{\circ} 0$ e foi cultivado com taboa, O SAC 5 foi constituído por brita $\mathrm{n}^{\circ} 0$ e não foi vegetado (testemunha).

Os SACs 2 e 4 apresentaram eficiências médias idênticas da ordem de 89,4\%, sendo que ambos tiveram como substrato brita $\mathrm{n}^{\circ} 0$ e areia, o primeiro cultivado com lírio do brejo e o último não vegetado (testemunha). Na tabela 3 a seguir são sumarizadas as eficiências dos sistemas e na Figura 4 a variação temporal das mesmas.

Tabela 3. Eficiência de remoção média, mínima e máxima por SAC e desvio padrão (DP).

\begin{tabular}{ccccc}
\hline Sistema & Média (\%) & $\begin{array}{c}\text { Máximo } \\
(\boldsymbol{\%})\end{array}$ & $\begin{array}{c}\text { Mínimo } \\
(\boldsymbol{\%})\end{array}$ & DP \\
\hline SAC1 & 91,5 & 93,9 & 85,8 & $\pm 2,6$ \\
SAC2 & 89,4 & 94,3 & 80,7 & $\pm 4,2$ \\
SAC3 & 90,4 & 95,2 & 79,0 & $\pm 5,0$ \\
SAC4 & 89,4 & 92,5 & 79,3 & $\pm 4,1$ \\
SAC5 & 90,4 & 94,9 & 80,2 & $\pm 4,3$ \\
SAC6 & 90,2 & 94,9 & 77,8 & $\pm 5,3$ \\
\hline
\end{tabular}

Nos primeiros 30 dias de avaliação dos sistemas até o dia 27/11/2009 foi observado um crescente aumento da eficiência de remoção de DBO. A partir de então, houve uma pequena queda nas eficiências dos sistemas exceto para o SAC 1 que teve sua eficiência reduzida após 43 dias (10/12/2009). Esta queda na eficiência média de 2,6\%, na remoção de DBO, foi atribuída a descarga de soda cáustica (hidróxido de sódio) no sistema. $\mathrm{O} \mathrm{pH}$ afluente neste momento apresentou valor igual 8, indicando a presença do sal, uma vez que a ARL afluente nesta pesquisa e também nos estudos de Matos et al. (2010a) apresentava características predominantemente ácidas com valores iguais a 5,0 e 3,78 respectivamente.

O SAC 1 provavelmente resistiu mais tempo às condições de alteração do $\mathrm{pH}$ por apresentar maior estabilidade biológica em seu ecossistema (maior resiliência do sistema), 
uma vez que por observações de campo, esta unidade apresentava melhores condições de desenvolvimento da vegetação cultivada e do biofilme junto ao substrato.

A partir do $50^{\circ}$ dia $(17 / 12 / 2009)$ os sistemas começaram a se recuperar elevando novamente sua eficiência, com destaque para o SAC 4 que teve seu aumento de eficiência elevado a partir do $43^{\circ}$ dia $(10 / 12 / 2009)$.

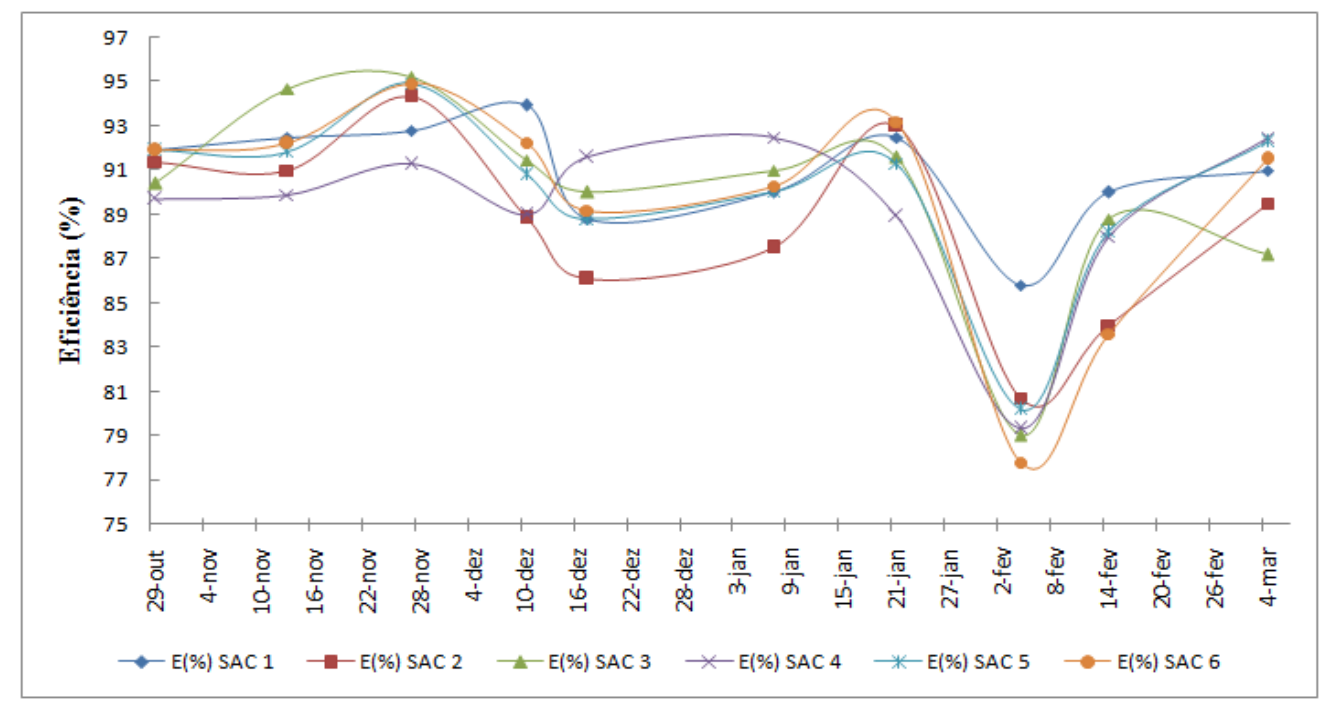

Figura 4. Série temporal da eficiência de remoção de DBO, durante 140 dias (outubro de 2009 a março de 2010 de operação dos SACs).

A partir do $71^{\circ}$ dia do monitoramento (07/01/2010) houve recuperação dos sistemas. Esta recuperação foi sendo intensificada até o dia 21 de janeiro de 2010 ( $85^{\circ}$ dia), exceto para o SAC 4, que apresentou declínio em relação aos demais tratamentos. Mesmo com a redução na eficiência do SAC4, tal diferença não apresentou diferença significativa $(p>0,05)$ pelo teste de análise de variância (ANOVA), nem pelos testes "post-hoc" de Dunnett, Student-Newman-Keuls e Bonferroni t-test, em relação às outras unidades experimentais.

Apesar do SAC 4 ter se recuperado antecipadamente em relação aos outro leitos, sua eficiência foi declinando no mês de janeiro de 2010, isto é, no $90^{\circ}$ dia experimental, acompanhando a tendência dos demais tratamento.

$\mathrm{O}$ declínio da eficiência em todas as parcelas experimentais a partir do $85^{\circ}$ dia experimental (21/01/2010) até o $99^{\circ}$ (04/02/2010), na remoção de DBO, foi atribuído ao pH afluente que apresentou valor igual a 11, valor distante da faixa ótima para crescimento bacteriano em torno da neutralidade $(6,5$ e 7,5) (Metcalf \& Eddy, 1991), associado a presença de maiores concentrações de hidróxido de sódio. A presença do sal nos sistema provocou toxicidade na entrada dos leitos o que acarretou o consolidado declínio da curva de eficiência no $99^{\circ}$ dia experimental, onde foram verificadas as menores remoções percentuais de DBO pelos sistemas entre 77,8 e 85,5, levando em consideração a TCO aplicada de $232 \mathrm{~kg} \mathrm{ha}^{-1} \mathrm{~d}^{-1}$. Mesmo com a queda da eficiência não foram verificadas diferenças significativas entre os tratamentos $(\mathrm{p}>0,05)$, por meio da análise de variância.

Observando a influência do $\mathrm{pH}$ básico do afluente, proporcionado pelo hidróxido de sódio, sobre a eficiência dos sistemas, verificou-se que valores de $\mathrm{pH}$ acima da neutralidade afetam os valores percentuais de remoção de DBO. No momento em que se aplicou a ARL com o $\mathrm{pH}$ de 8 houve uma queda na média geral dos tratamentos de 2,6\%. A aplicação da ARL com pH de 11 reduziu a eficiência média geral em 11,3\%. Mesmo com o declínio das eficiências não foram detectadas diferenças significativas entre os percentuais de remoção dos tratamentos pelo teste de análise de variância (ANOVA), nem pelos testes "post-hoc" de Dunnett, Student-Newman-Keuls e Bonferroni t-test. 
Os valores de $\mathrm{pH}$ médio nas saídas dos sistemas, no momento em que se aplicou a ARL com pH 8 e 11, apresentaram valor 6 e 8, respectivamente, indicando boa capacidade de tamponamentos dos leitos. Mesmo sujeitos ao $\mathrm{pH}$ básico, os SACs foram capazes de manter a faixa ideal para decomposição do material orgânico biodegradável e também para descarte do efluente em curso de água preconizados pela resolução CONAMA 430/2011.

Por meio das análises do $111^{\circ}$ dia, 14/02/2010, foi verificado recuperação dos sistemas, elevando novamente suas eficiências. $\mathrm{O}$ aumento acerca da eficiência pode ser constatado na amostra do dia 04/03/2010 (140 dias), exceto para o SAC 3, que apesar de ter elevado potencialmente sua remoção de DBO obteve um valor inferior a análise anterior do dia $14 / 02 / 2010$.

A análise de variância (ANOVA), assim como os testes "post-hoc" (Dunnett, StudentNewman-Keuls e Bonferroni t-test) evidenciaram que não houve diferença significativa $(\mathrm{p}>0,05)$ na eficiência de remoção de DBO entre as parcelas estudadas. Sendo assim, não houve influência das espécies cultivadas nos SACs ou a ausência delas sobre os resultados, confirmando que a remoção deste parâmetro dar-se-á primordialmente por mecanismos físicos e microbiológicos, para DBO particulada e DBO solúvel, respectivamente.

A operação dos SACs por bateladas com tempo de ciclo de dois dias mostrou-se eficiente para o tratamento da ARL. Matos et al. (2010a) testando estes sistemas com água residuária de laticínios (ARL) obteve uma remoção de DBO média de 78,5 \% e máxima de $96,3 \%$ utilizando forrageiras como vegetações, operados em fluxo contínuo sub superficial com substrato composto por brita $\mathrm{n}^{\circ} 0$, aplicando uma TCO variável entre parcelas entre $66 \mathrm{e}$ $570 \mathrm{Kg}$ DBO ha ${ }^{-1} \mathrm{~d}^{-1}$. Neste estudo os autores identificaram maiores remoções de DBO em SACs que receberam maiores TCOs. Em comparação com a presente pesquisa, o maior valor de remoção de DBO de 96,3 \% pelos SACs, encontrado por Matos et al. (2010a), foi atribuído ao maior TDH utilizado na pesquisa pelos autores, de 4,8 dias.

Mantovi et al. (2003) atingiram uma eficiência de 93,7\% operando dois SAC de fluxo sub superficial aplicando uma TCO inferior ao da presente pesquisa, de $19 \mathrm{Kg}_{\mathrm{DBO}} \mathrm{ha}^{-1} \mathrm{~d}^{-1}$, com TDH de 10 dias. Os autores utilizaram cascalho lavado e brita $\mathrm{n}^{\circ} 3$ como meio suporte, cultivando a macrófita Phragmites australis. O valor remoção de DBO encontrado pelos autores supera os da presente pesquisa em função do TDH adotado de 10 dias, associados a menores TCOs aplicadas.

Matos et al. (2010b) em sua pesquisa com águas residuárias da suinocultura tratadas por SACs com TDH de 4,8 dias, verificaram em todas as amostras coletadas eficiência de tratamento superior a $50 \%$, variando entre 84 e $88 \%$, com médias estatisticamente iguais entre si, (p>0,05) em relação a $\mathrm{DBO}_{\text {total }}$. A eficiência média nesta pesquisa variou de 89,4 a 91,2 valores próximos aos encontrados pelos autores.

Fia et al. (2012), tratando efluentes da suinocultura (ARS) por meio de SACs em escala laboratorial, condicionados a uma temperatura de $20^{\circ} \mathrm{C}$, sob duas taxas de carregamento orgânico (TCOs) de 246 e $328 \mathrm{Kg}$ DBO ha ${ }^{-1} \mathrm{~d}^{-1}$, com TDH de 1,463 e 1,052 dias, obtiveram satisfatórias eficiências de remoção de DBO entre 73 e $66 \%$. Na presente pesquisa, onde se aplicou uma TCO de $232 \mathrm{~kg} \mathrm{ha}^{-1} \mathrm{~d}^{-1}$, com tempo de ciclo de dois dias, as remoções foram superiores, levando em consideração o maior tempo de contato do efluente com o meio e também a amplitude de variação térmica do ar que variou de 20 a $23,1^{\circ} \mathrm{C}$, no período de condução do experimento.

No presente estudo, os SACs operando em bateladas apresentaram eficiências semelhantes aos trabalhos de Mantovi et al. (2003), tratando efluentes de laticínios com TDH de 10 dias e Matos et al. (2010b) tratando efluentes da suinocultura com TDH de 4,8 dias, onde os SACs operaram em escoamento contínuo sub superficial. O tempo de detenção empregado nesta pesquisa ( 2 dias), foi considerado satisfatório para tratamento da ARL após tratamento preliminar. 
Neafsey e Clausen (1994) trataram efluentes de laticínios em SACs, adotando um tempo de residência hidráulica de 27 dias, cultivando as macrófitas Typha spp., Phragmites spp. e Scirpus americanus. Estes autores observaram uma remoção máxima de 99,1\% de DBO. O valor superior encontrado pelos autores na remoção de $\mathrm{DBO}$, em relação a presente pesquisa, foi atribuído ao tempo de retenção elevado de 27 dias.

\section{CONCLUSÕES}

Os testes estatísticos evidenciaram que não houve diferenças significativas na remoção de $\mathrm{DBO}$, nem de regulação do $\mathrm{pH}$, pelos leitos vegetados em relação aos não vegetados (testemunhas).

Os SACs apresentaram características de efeito tampão, mantendo as faixas de $\mathrm{pH}$ efluentes dentro dos limites exigidos pela Legislação Federal vigente CONAMA 430/2011, para lançamento de efluentes em curso de água, não havendo diferenças significativas entre as parcelas estudadas.

A operação de SACs por bateladas demonstrou ser uma eficiente concepção de tratamento na remoção de compostos orgânicos biodegradáveis e regulação de pH.

O tempo de ciclo (TC) de dois dias possibilitou que as reações bioquímicas ocorressem com sucesso.

Os resultados obtidos neste trabalho, embora preliminares, indicaram que os sistemas alagados construídos podem se utilizados para o tratamento de águas residuárias de laticínios, após passagem por sistema preliminar composto por: grade, desarenador e caixa de gordura.

\section{REFERÊNCIAS}

AMERICAN PUBLIC HEALTH ASSOCIATION - APHA; AMERICAN WATERWORKS ASSOCIATION - AWWA; WATER ENVIRONMENT FEDERATION - WEF. Standard methods for the examination of water and wastewater. 21th. ed. Washington, 1998.

BRASIL. Conselho Nacional de Meio Ambiente. Resolução CONAMA nº 430, de 13 de maio de 2011. Diário Oficial [da] União, Brasília, DF, 16 maio 2011, p. 89.

DRIZO, A.; TWOHIG, E.; WEBER, D.; BIRD, S.; ROSS, D. Constructed wetlands for dairy effluent treatment in Vermont: two years of operation. In: INTERNAT. CONF. WETLAND SYSTEMS FOR WATER POLLUTION CONTROL, 10., Lisbon, Portugal. Proceedings..., Lisbon, 2006. p. 1611-1621.

FIA, F. R. L.; MATOS, A. T.; FIA, R.; BORGES, A. C.; TEIXEIRA, D. L. Remoção de matéria orgânica e determinação de parâmetros cinéticos em sistemas alagados construídos em escala laboratorial. Revista Acta Scientiarun. Technology, Maringá, v. 34, n. 2, p. 149-156, 2012.

GASIUNAS, V.; STRUSEVICIUS, Z.; STRUSEVICIÉNE, M.S. Pollutant removal by horizontal subsurface flow constructed wetlands in Lithuania. Journal Environ. Sci. Health, Philadelphia, v. 40, p. 1467-1478, 2005. http:/dx.doi.org/10.1081/ESE200055889

HEALY, M. G.; CAWLEY, A. M. The nutrient processing capacity of a constructed wetland in western Ireland. Journal of Environmental Quality, New Jersey, v. 31, n. 5, p. 1739-1747, 2002. http://dx.doi.org/10.2134/jeq2002.1739 
HEALY, M. G.; RODGERS, M.; MULQUEEN, J. Treatment of dairy wastewater using constructed wetlands and intermittent sand filters. Bioresource Technology, v. 98, p. 2268-2281, 2007. http://dx.doi.org/10.1016/j.biortech.2006.07.036

MANSOR, M. T. C. Uso de leitos de macrófitas no tratamento de águas residuárias. 1998. 106f. Dissertação (Mestrado em Engenharia Agrícola) - Universidade Estadual de Campinas, Campinas, 1998.

MANTOVI, P.; MARMIROLI, M.; MAESTRI, E.; TAGLIAVINI, S.; PICCININI, S.; MARMIROLI, N. Application of a horizontal subsurface flow constructed wetland on treatment of dairy parlour wastewater. Bioresource Technology, v. 88, n. 13, p. 85-94, 2003 .

MATOS, A. T.; ABRAHÃO, S. S.; PEREIRA, O. G. Desempenho agronômico de capim tifton 85 (cynodon spp) cultivado em sistemas alagados construídos utilizados no tratamento de água residuária de laticínios. Revista Ambi-Água, Taubaté, v. 3, n. 1, p. 43-53, 2008. http://dx.doi.org/10.4136/ambi-agua.41

MATOS, A. T.; ABRAHÃO, S. S.; BORGES, A. C.; MATOS, M. P. Influência da taxa de carga orgânica no desempenho de sistemas alagados construídos cultivados com forrageiras. Revista Engenharia Sanitária e Ambiental, Rio de Janeiro, v. 15, n. 1, p. 83-92, 2010a.

MATOS, A. T.; FREITAS, W. S.; LO MONACO, P. A. V. Eficiência de sistemas alagados construídos na remoção de poluentes de águas residuárias da suinocultura. Revista Ambient. Água, Taubaté, v. 5, n. 2, p. 119-132, 2010b. http://dx.doi.org/10.4136/ambiagua. 142

MENDONÇA, H. V. Avaliação da eficiência de sistemas alagados construídos em operação por bateladas no tratamento de efluentes da indústria de laticínios. 2011. 113f. Dissertação (Mestrado em ecologia aplicada ao manejo e conservação de ecossistemas) - Universidade Federal de Juiz de Fora, Minas Gerais, 2011.

MENDONÇA, H. V. Remoção de nitrogênio e fósforo de águas residuárias de laticínios por sistemas alagados construídos operando em bateladas. Revista Ambient. Água, Taubaté, v. 7, n. 2, p. 75-87, 2012. http://dx.doi.org/10.4136/ambi-agua.805

METCALF \& EDDY. WASTEWATER ENGINEERING - TREATMENT, DISPOSAL AND REUSE. NEW YORK: MCGRAW HILL, 1991. 1334 P.

NEAFSEY, J. A.; CLAUSEN J. C. Constructed Wetlands for Treatment of Milkroom Wastewater. Internal report. [S.1.: s.n.], 1994. 122p.

REAVES, R. Evaluation of Free Water Surface Constructed Wetlands for Treatment of Livestock Waste in Indiana. 122p. Ph.D. Dissertation, Purdue University, Lafayette, Indiana, 1995. 